Portland State University

PDXScholar

6-16-2021

\title{
Music Education, Child Development, and Academic Achievement: A Review of Recent Literature
}

Connor M. Welsh

Portland State University

Follow this and additional works at: https://pdxscholar.library.pdx.edu/honorstheses

Part of the Child Psychology Commons, Developmental Psychology Commons, and the Music Education Commons

Let us know how access to this document benefits you.

\section{Recommended Citation}

Welsh, Connor M., "Music Education, Child Development, and Academic Achievement: A Review of Recent Literature" (2021). University Honors Theses. Paper 1041.

https://doi.org/10.15760/honors.1067

This Thesis is brought to you for free and open access. It has been accepted for inclusion in University Honors Theses by an authorized administrator of PDXScholar. Please contact us if we can make this document more accessible: pdxscholar@pdx.edu. 
Music Education, Child Development, and Academic Achievement: A Review of Recent Literature

by

Connor Welsh

An undergraduate honors thesis submitted in partial fulfillment of the requirements for the degree of

Bachelor of Science

in

University Honors

and

Psychology

Thesis Advisor

Jeslin Hancock

Portland State University 


\begin{abstract}
In this literature review, the effect of music education on child development and academic success was evaluated. The claim that music education is beneficial to both child development and academic success has grown as a popular idea in recent decades. One example of this is the popular practice of having children or infants listen to classical music. This literature review aimed to evaluate this claim by examining a sample of the past ten years of research articles. The literature review was divided into two main categories: music education and cognitive development and music education and social-emotional development. Initially, it was hypothesized that the scientific literature would uphold the claim that music education is beneficial to child development and academic success, and the hypothesis was supported. It was found that music education has beneficial effects on several domains of development, some of which would benefit academic success as well. The literature supported the claim that music education positively affects academic success through extensive correlational research and research on the effects of music education on executive functions.
\end{abstract}




\section{Introduction}

Music is something that connects us all. Across all cultures, classes, and divides, music is something that everyone can participate in and enjoy. Music programs in public schools are an essential part of furthering the tradition of music-making, and for many people, are the start of their music careers. However, budget cuts have increasingly plagued primary education in the United States since 2008 (Leachman et al., 2017). It seems the arts are forever clinging to the edge of academic obscurity, even though the notion that arts and music are developmentally beneficial has been around for decades. The purpose of this literature review was to evaluate this claim and to determine whether music education is developmentally beneficial for elementary school students. The literature review was broken down into two broad categories: music education and cognitive development and music education and social-emotional development. These categories were chosen as vital areas of child development and areas where music education may support and serve as a protective factor in a child's development. Some of these aspects of development are also overlooked in modern curriculum. Children must be supported holistically, especially in primary school, which is a sensitive time for development (Chen et al., 2021). Adequate support for all areas of development has the potential to improve children's academic and overall well-being. It was hypothesized that an extensive literature review would reveal that music education has a significantly positive impact on cognitive and social-emotional development. This result would show that music education is an effective tool to support elements of development and academic success.

\section{Methods}

An extensive literature search was conducted via PsychINFO, Google scholar, and Proquest. Literature was pulled from catalogs that were available through the Portland State 
University library's subscriptions. Articles were chosen that focused on the age range of early to middle childhood during which children would be attending primary school. This age range was chosen because primary school music programs are often children's first introduction to a formal and structured form of music-making and participation. Children are also going through rapid cognitive development during this age, making this a sensitive period of development and, therefore, an optimal time to implement music programs and activities (Chen et al., 2021). The term "music education" was used in this paper to denote any type of music training, whether through private lessons or classes in public school settings. In addition to music education, some articles researching the effects of music interventions were examined. These are separate from music education as they are musical activities that have a specific purpose and typically last for a shorter length of time than general music education programs. Finally, the sources included in this literature review were from the past ten years, ensuring that the information provided current and captured the evolution of this discourse.

\section{Literature review}

\section{Music Education and Cognitive Development}

One of the most prevalent ideas among teachers, researchers, parents, and the public, is that music education and lessons can improve several aspects of cognitive development, including language development, executive function, intelligence, and academic success. However, in reviewing the literature to evaluate this widely held belief, it was found that the actual effects of music education on cognitive development and academic achievement are much less decisive.

\section{Music Education, Intelligence, and Academic Achievement}


Several studies have suggested that music education positively affected academic achievement (Southgate \& Roscigno, 2009; Holochwost et al., 2017; Guhn et al., 2020). Southgate and Roscigno (2009) sought to address past research's limitations by accounting for socioeconomic status (SES), music involvement, and using a large sample size. They used data from the nationally representative Early Childhood Longitudinal Study and the National Educational Longitudinal Study to examine the relationship between academic success and music involvement while controlling for previous academic achievement. From Southgate and Rescigno's (2009) analysis, it was found that music involvement was associated with significantly higher academic achievement in primary school children and adolescents. Holochwost et al. (2017) developed these findings by randomly selecting children to participate in an after-school orchestral instrument training program. The researchers found that participation in the program for three years positively affected students' executive function and academic performance on standardized tests. Despite the findings from Holochwost et al. (2017) and Southgate and Roscigno (2009), there has been some debate about the actual effects of music education.

A meta-analysis by Sala and Gobet (2017) determined that only moderate enhancements were found across research papers covering music education's effects on academic achievement. They also found that the quality of study design was negatively correlated to the amplitude of the effects of music education academic achievement or intelligence. Sala and Gobet (2020) also repeated their meta-analysis on the relationship between music education, intelligence, and academic success. They confirmed and expanded upon the findings of their 2017 review, stating that music education or training had no bearing on academic success or intelligence. They came to this conclusion through an extensive literature review on studies that had used experimental 
designs with random assignment and controls. There is strong evidence from these reviews that there is no direct causal relationship between music education and intelligence or academic performance. However, Guhn and colleagues (2020) provided contrary evidence with their largescale analysis of students in British Columbia that included more than 110,000 participants. Even when controlling for socioeconomic factors, previous academic achievement, cultural background, and sex, students who engaged in music education had higher levels of academic achievement than students not engaged in any music education. In addition, Hogenes et al. (2016) studied a group of 21 classes with a total of 500 students to see if a music composition classroom activity would influence academic performance, intelligence, or music achievement. Hogenes et al. (2016) randomly selected classrooms to receive the composition in a quasiexperimental design and found that students that received the lesson had better performance on reading comprehension. Although this study did not show that music education or intervention leads to higher intelligence or improved academic achievement, it did show evidence that music education can support skills vital for academic achievement.

This was the primary oversight of Sala and Gobet's review (2020). Music may not directly lead to higher intelligence or academic achievement, but evidence suggests that music education can improve essential skills that help those outcomes.

\section{Music Education and Language Development}

Evidence has been found that music education supports other factors that facilitate academic success, such as language development. Several studies have found that introducing music into early learning environments, such as preschool and primary school, may help language development (Carr et al., 2014; Chobert et al., 2014; Hogenes et al., 2016; Kraus et al., 2014; Linnavalli et al., 2018). In a study by Kraus et al. (2014), researchers studied whether a 
community-based music program led to any biological changes in the neural processing of speech. The researchers utilized a randomized control design with 44 students and found that music training longer than one year led to improvements in specific neurological pathways related to language skills. Similar results were also found by Chobert et al. (2014) in a longitudinal study of third graders over the course of two years. Thirty-seven children from nonmusical backgrounds were recruited for the study and randomly assigned to either music or art lessons. Chobert et al. (2014) measured the children's ability to perceive whether two syllables matched. This measure was used to indicate the development of speech recognition. After the 12 months of training, the children in the music training group showed significantly improved results compared to the art lessons group. Chobert et al. (2014) stated that this provides evidence that there is a causal link between music education and language development.

Another area of research overlooked in previous literature reviews and meta-analyses is the effect music education has on the development and executive functions and how these skills can improve academic outcomes.

\section{Music Education and Executive Function}

Some of the most recent research on the effects of music education and cognitive development focuses on the development of executive control (Chen et al., 2021). Executive control or executive function abilities develop rapidly during middle childhood when children are in primary school. Successful development of attention and inhibition control is essential for academic success (Best et al., 2011). Putkinen et al. (2015) found that musically trained children scored better on executive function assessments in their study on neural auditory skills. This study argued that these results suggest transfer effects to other developmental skills such as attention and inhibition. The study by Putkinen et al. (2015) consisted of a longitudinal 
examination of 133 children and controlled for socioeconomic status and other confounding variables. Throughout the longitudinal study, they measured the improvement in children's response to discriminating between auditory stimuli and tested whether the music training provided improved executive function. They found that the musical training led to accelerated maturation of executive function areas of the brain that lead to the participants being better at controlling their attention. As Putkinen et al. (2015) explained, these findings demonstrated that attention control is not only important to the domain of music education but also a vital skill that can help children succeed in all other aspects of school. Putkinen et al. (2015) acknowledged that even though their control and experimental groups showed no difference in executive or auditory control at the beginning of the study, it does not entirely remove the possibility that genetic factors cannot explain the differences in performance. This factor has made it difficult to determine if the effects of music training should be attributed to the experience children gain through music education or the difference in genetic predispositions towards better attention, drive to learn, and personality.

Chen et al. (2021) further explored the effects of music education on the development of executive control. The study consisted of two separate experiments. One focused on the differences in executive function between musically trained children and non-musically trained children; the other focused on differences between the age at which the music training started. All participants were asked to perform several tasks to evaluate executive control abilities, and the researchers found significant differences between the musically and non-musically trained children. The most notable differences were found between the participants who started music training early and the non-musically trained students. The studies by Chen et al. (2021) and Putkinen et al. (2015) showed the importance of music education to executive function 
development and provided evidence for a more comprehensive inclusion of music in education from an early age. Chen et al. (2021) also provided evidence for the importance of when music training is started. Most formal music training in the U.S. does not begin until middle or late childhood; however, the most significant benefit from this training can be found by starting that training as early as possible (Chen et al., 2021).

Further evidence for these benefits can be found with Joret et al. (2017), who studied inhibitory control and music education. Their study emphasized addressing some of the methodological faults from previous studies by controlling for confounding factors such a socioeconomic status and language skills. The researchers also carefully defined what they categorized as musical training and collected data on what type of music training the participants received, the age at which music training started, and the amount of practice each week. Joret et al. (2017) determined that inhibitory control was significantly increased in children who participated in music over their control group that had not received music training.

Throughout these studies, the researchers have attributed executive function and behavior improvements to specific music training and education properties, such as the need for selective attention and working memory (Joret et al., 2017; Chen et al., 2021). Music training programs that nurtured these specific skills provided benefits beyond musical ability as these are essential skills used throughout academia and everyday life (Miyake et al., 2000; Riggs et al., 2006; Xue et al., 2019). However, some researchers have found opposing results for the efficacy of music training on executive function. Schellenberg (2011) found that children with higher IQ are more likely to participate in music lessons and perform better on cognitive tests apart from tests on executive function. These claims have since been refuted as some of the tests used by Schellenberg (2011) were designed to be used on adults, not children (Degé et al., 2011). Others 
have argued that research should focus more on the age range and types of music instruction being examined as they may have varying effects (Norgaard et al., 2019). Norgaard et al. (2019) sought to address this by explicitly examining how jazz improvisation affected the executive function of middle school students in seventh and eighth grade. The researchers found that the jazz improvisation instruction had different effects between the two grades. Significant positive effects were only found in the eighth-graders and not seventh-graders suggesting that the effects of music education may differ when music education or training is introduced at different ages. Despite the possibility that some of the effects of music education can be explained due to genetic differences, music education has been associated with improved executive function across inhibition, attention switching, and cognitive flexibility for much of the past decade of research. These consistent results provide strong evidence for music education and training to supplement executive function development. Furthermore, executive function development has been strongly associated with academic achievement, and training executive functions have been shown to improve performance in other academic areas such as math and reading (Best et al., 2011).

\section{Music Education and Social-Emotional Development}

Over the past decade, it has become increasingly clear that emotion regulation and expression skills are vital to academic success, especially in early education (Graziano et al., 2007). It is also well known that emotional and mental health can profoundly affect students' academic success and development outcomes (Graziano et al., 2007). Furthermore, minority groups and students with disabilities are more at risk for trauma or mental disorders that can impact their academic future (Graziano et al., 2007). The impact of music education and 
interventions on social-emotional development is actively being discovered, and research done in this field has led to some promising results so far.

\section{Music Education and Emotional Intelligence}

One example of the impact that music education can have on emotional intelligence is a study by Kim and Kim (2018) that measured the effects of instrument performance on several social-emotional outcomes, including emotional intelligence, anxiety, and aggression. The researchers found that their intervention, which consisted of a program that taught the children to play the flute, did not affect the participant's total level of emotional intelligence, aggression, or anxiety but did increase their ability to perceive emotion in others. They also found that their intervention caused a noticeable but not significant reduction in physical and verbal aggression in the participants from the intervention group compared to participants in the control group. It is worth noting that this study was conducted only at two primary schools in Seoul and used convenience sampling to recruit their participants, meaning that the findings only suggest possible effects and are not generalizable.

This positive effect that music education has on social-emotional development factors such as self-esteem and emotion regulation have also been replicated in disadvantaged populations (Alemán et al., 2017; Ho et al., 2011; Rickard et al., 2013; Zapata \& Hargreaves, 2018). In Alemán et al.'s (2017) study of the El Sistema music program in Venezuela, they found that the program had the most positive effect on boys who had been exposed to violence or who had less educated mothers. These studies pointed to the possibility that after-school music programs and other forms of music education can positively impact social and emotional development. One of the most important contributions of this research is that it addressed some of the most common research limitations noted in music education research. Many reviews of 
the field have been critical of past studies for the lack of attention to controlling for possible confounding factors such as socioeconomic status (Elpus, 2013). However, recent studies on the effects of music programs on social-emotional development have effectively addressed these concerns by controlling these factors in data analyses. Researchers must account for the accessibility of their programs to underprivileged and low socioeconomic status children while researching the effects of music education.

\section{Music Education and Social Skills}

Part of what makes music beneficial is that it is a social activity. Music programs provide a safe social environment where children can participate in the same activity non-competitively. Some studies have explored whether this can lead to benefits in developing prosocial behaviors and general social development. One example of this can be found with a study by Ho et al. (2011), which found that participation in group drumming among low-income fifth graders led to significant improvements in social-emotional behavior across several domains, including withdrawnness, attention, anxiety, and defiance.

Researchers have also studied the effectiveness of music programs that are already integrated with a school's curriculum. Brown and Sax (2013) examined The Kaleidoscope program provided by the Settlement Music School, which provides an arts-enrichment program for low-income children in their community who attended Head Start. They compared the socialemotional development of students who attended a Head Start with the Kaleidoscope program to students who only attended regular Head Start preschool. Both Head Start schools served the same community. Brown and Sax (2013) evaluated the functions of music listening and found that students who participated in Kaleidoscope had enhanced development of emotion regulation 
skills and emotional readiness to learn. The authors describe emotional readiness to learn as the level of emotional skills needed to succeed in school.

Music education's effect on prosocial behavior was also measured directly by Schellenberg et al. (2015) when they studied the differences between primary school students who had access to an education enhanced with music and those who did not. The researchers found that children with lower social skills at the start of the study grew the most out of either the control or experimental group. Schellenberg et al. (2015) attributed this to the peer synchrony achieved during group music lessons. Music education and training provide a social environment that positively influences both emotional and social development.

\section{Discussion}

The review of literature studying the effects of music education, interventions, training, and programs found that they can be beneficial for children's development and academic outcomes in primary education. This assessment came from many articles that show benefits to academic achievement, executive functions, emotion regulation, and prosocial skills. Over the past ten years, studies have been carried out multiple times to confirm these effects. The implications of these findings are widespread. It seems that music education and programs uniquely support students' development and academic success in a more holistic way than other programs. This is due to the unique social nature of music education. Other group activities such as sports may also support development, but music does so in a noncompetitive and entirely collaborative way.

\section{Implications of Current Research}


One way that music programs affect emotional and social development is through selfesteem. Several reviewed articles found that the music programs had positive effects on selfesteem (Zapata \& Hargreaves, 2018; Rickard et al., 2013), and these articles suggested that this increase could be due to a sense of shared achievement and community. Emotion perception is another essential skill that music education benefits (Kim \& Kim, 2018). These skills are vital for academic success and social-emotional well-being, but music education can also directly affect children's cognitive development in primary school.

The review of music's effect on executive function demonstrated how development and academic success could be supported holistically through music programs, interventions, and education. As seen from the nationally representative study by Best et al. (2011), the development of executive functions and academic achievement were highly related. However, Executive function development is beneficial beyond just academic benefits. The development of executive functions helps with higher-ordered thinking and includes inhibitory control, cognitive flexibility, and working memory (Miyake et al., 2000). These skills can be used beyond the classroom, and some studies have shown that healthy development of executive skills has been shown to help both physical and mental health (Riggs et al., 2006; Xue et al., 2019).

Another important implication of the current research on music education and child development is that it is an accessible and cost-effective way to enrich programs. As shown by several research studies in this review, music education programs appear to be most beneficial to children growing up in school districts that serve low-income families and children experiencing adversity across multiple domains (Alemán et al., 2017; Hedemann \& Frazier, 2017; Zapata \& Hargreaves, 2018). These music education programs are community-based and appear to provide a structured, safe environment for all children to experience developmental benefits. 


\section{Limitations and Future Directions}

There were some significant limitations observed among the articles that were included in this literature review. One of the most concerning limitations was the lack of experimental studies. Many studies on the relationship between music education, development, and academic achievement were either correlational or observational in nature. While these types of studies provide insights into possible relationships between variables, they do not imply causation. The correlational work supporting the idea that music education can improve academic achievement has often fallen short in controlling for confounding variables such as socioeconomic status (Elpus, 2013). The idea that music education can improve academic outcomes has also been subject to a correlation versus causation fallacy. Corrigall et al. (2013) showed that much of the research on this topic had used correlational designs to show the association between academic success and music education without considering individual differences in children's personalities. They provided evidence in their study that children who tested higher in conscientiousness and openness to experience were more likely to take music lessons or continue with music education and do better in school. Because of this lack of experimental studies, music education's specific effect on development and academic success has yet to be determined. This also means that many of the mechanisms behind the supposed relationship between these factors are undiscovered. Non-experimental studies without random assignment or blinds are also more susceptible to confirmation bias. The idea that music positively affects education and development is long-standing, and researchers may knowingly or unknowingly have inflated the supposed effects of music interventions and programs to fit within this paradigm (Sala \& Gobet, 2020). The issue of non-experimental study design is not an issue that has not been ignored, however. 
Complications with random assignment and selection may prohibit researchers from using an experimental study design. These can be difficult to achieve when studying the effectiveness of music programs that are already in place. In addition, it is common for families and children to drop out of studies or for children not to want to continue with the assigned music intervention when random assignment is implemented. Researchers have bypassed these complications by using convenience sampling methods to collect data on children or families that have already chosen to be a part of a music program. This could have introduced confounding variables like musical aptitude and determination to learn, which created an alternate explanation for whatever effect the researchers found (Swaminathan et al., 2017).

Another major limitation was a lack of consistency with the operationalization of what music training, education, or programs meant. The kinds and types of music education were highly varied between studies with little to no consistency. This makes any meta-analysis of the field much more difficult to accomplish as it clouds the overarching effects of music education. To accurately study the effects of music education and training, there needs to be more collaboration between researchers to standardize the definition of music training or education. Standardization could include creating a way of evaluating and scoring music education so that the types of music education, training, or intervention can be compared and analyzed separately.

Despite these issues, the evidence for music education having a positive effect on academic success and several domains of development is still valid. Studies like Guhn et al. (2020) that provided population-level analysis have consistently shown the positive association between music education and academic success. However, to determine the cause or mechanism behind this association, the concerns outlined above need to be addressed.

\section{Conclusion}


In this literature review, research on the relationship between music education and academic achievement and development was examined. A sample of articles was collected and divided into two main categories: cognitive development and social-emotional development. In the review of articles on the impact of music education on academic achievement and intelligence, it was observed that music education did not directly cause academic achievement or heighten intelligence but could be a mediating factor that enhances essential skills. This was demonstrated by studies on executive function, where it was determined that several types of music education led to improvements in two of the three main types of executive function: attention switching and inhibitory control. Finally, in the social-emotional section, it was established that music education positively affected the development of emotion perception, regulation, and other emotional development factors such as self-esteem. It was also found that music education helped develop prosocial skills, especially among disadvantaged children. There were also limitations present in this discourse. The overarching issue with the literature on music education, development, and academic achievement was that studies lacked consistency and experimental design. These concerns made making any overarching deductions on the effects of music education much more difficult. Nevertheless, it was found that music education positively affects child development and is an accessible way to improve primary school curriculum. The benefits from music programs do not always lead to direct improvement to academic success, but the support music education provides to cognitive and social-emotional development can help children develop the skills they need to succeed. From academics to social interactions to emotional recognition, music has a lesson for everyone. 


\section{References}

Alemán, X., Duryea, S., Guerra, N. G., McEwan, P. J., Muñoz, R., Stampini, M., \& Williamson, A. A. (2017). The effects of musical training on child development: A randomized trial of El Sistema in Venezuela. Prevention Science, 18(7), 865-878. https://doi.org/10.1007/s11121-016-0727-3

Best, J. R., Miller, P. H., \& Naglieri, J. A. (2011). Relations between executive function and academic achievement from ages 5 to 17 in a large, representative national sample. Learning and individual differences, 21(4), 327-336. https://doi.org/10.1016/j.lindif.2011.01.007

Brown, E. D., \& Sax, K. L. (2013). Arts enrichment and preschool emotions for low-income children at risk. Early Childhood Research Quarterly, 28(2), 337-346. https://doi.org/10.1016/j.ecresq.2012.08.002

Carr, K. W., White-Schwoch, T., Tierney, A. T., Strait, D. L., \& Kraus, N. (2014). Beat synchronization predicts neural speech encoding and reading readiness in preschoolers. Proceedings of the National Academy of Sciences, 111(40), 14559-14564. https://doi.org/10.1073/pnas.1406219111

Chen, J., Scheller, M., Wu, C., Hu, B., Peng, R., Liu, C., Liu, S., Zhu, L., \& Chen, J. (2021). The relationship between early musical training and executive functions: Validation of effects of the sensitive period. Psychology of Music, 0305735620978690. https://doi.org/10.1177/0305735620978690

Chobert, J., François, C., Velay, J. L., \& Besson, M. (2014). Twelve months of active musical training in 8-to 10-year-old children enhances the preattentive processing of syllabic 
duration and voice onset time. Cerebral Cortex, 24(4), 956-967. https://doi.org/10.1093/cercor/bhs377

Corrigall, K. A., Schellenberg, E. G., \& Misura, N. M. (2013). Music training, cognition, and personality. Frontiers in psychology, 4, 222. https://doi.org/10.3389/fpsyg.2013.00222

Degé, F., Kubicek, C., \& Schwarzer, G. (2011). Music lessons and intelligence: A relation mediated by executive functions. Music Perception, 29(2), 195-201. https://doi.org/10.1525/mp.2011.29.2.195

Elpus, K. (2013). Is it the music or is it selection bias? A nationwide analysis of music and nonmusic students' SAT scores. Journal of Research in Music Education, 61(2), 175-194. https://doi.org/10.1177/0022429413485601

Graziano, P. A., Reavis, R. D., Keane, S. P., \& Calkins, S. D. (2007). The role of emotion regulation in children's early academic success. Journal of School Psychology, 45(1), 319. https://doi.org/10.1016/j.jsp.2006.09.002

Guhn, M., Emerson, S. D., \& Gouzouasis, P. (2020). A population-level analysis of associations between school music participation and academic achievement. Journal of Educational Psychology, 112(2), 308. http://doi.org/10.1037/edu0000376

Hedemann, E. R., \& Frazier, S. L. (2017). Leveraging after-school programs to minimize risks for internalizing symptoms among urban youth: Weaving together music education and social development. Administration and Policy in Mental Health and Mental Health Services Research, 44(5), 756-770. https://doi.org/10.1007/s10488-016-0758-X 
Ho, P., Tsao, J. C. I., Bloch, L., \& Zeltzer, L. K. (2011). The impact of group drumming on social-emotional behavior in low-income children. Evidence-Based Complementary and Alternative Medicine, 2011, Article 250708. https://doi.org/10.1093/ecam/neq072

Hogenes, M., van Oers, B., Diekstra, R. F. W., \& Sklad, M. (2016). The effects of music composition as a classroom activity on engagement in music education and academic and music achievement: A quasi-experimental study. International Journal of Music Education, 34(1), 32-48. https://doi.org/10.1177/0255761415584296

Holochwost, S. J., Propper, C. B., Wolf, D. P., Willoughby, M. T., Fisher, K. R., Kolacz, J., Volpe, V. V., \& Jaffee, S. R. (2017). Music education, academic achievement, and executive functions. Psychology of Aesthetics, Creativity, and the Arts, 11(2), 147-166. https://doi.org/10.1037/aca0000112

Joret, M. E., Germeys, F., \& Gidron, Y. (2017). Cognitive inhibitory control in children following early childhood music education. Musicae Scientiae, 21(3), 303-315. https://doi.org/10.1177/1029864916655477

Kim, H. S., \& Kim, H. S. (2018). Effect of a musical instrument performance program on emotional intelligence, anxiety, and aggression in Korean elementary school children. Psychology of Music, 46(3), 440-453. http://doi.org/10.1177/0305735617729028

Kraus, N., Slater, J., Thompson, E. C., Hornickel, J., Strait, D. L., Nicol, T., \& White-Schwoch, T. (2014). Music enrichment programs improve the neural encoding of speech in at-risk children. Journal of Neuroscience, 34(36), 11913-11918. https://doi.org/10.1523/JNEUROSCI.1881-14.2014 
Leachman, M., Masterson, K., \& Figueroa, E. (2017, November 29). A Punishing Decade for School Funding. Center on Budget and Policy Priorities. https://www.cbpp.org/research/state-budget-and-tax/a-punishing-decade-for-schoolfunding

Linnavalli, T., Putkinen, V., Lipsanen, J., Huotilainen, M., \& Tervaniemi, M. (2018). Music playschool enhances children's linguistic skills. Scientific Reports, 8(1), 8767. https://doi.org/10.1038/s41598-018-27126-5

Miyake, A., Friedman, N. P., Emerson, M. J., Witzki, A. H., Howerter, A., \& Wager, T. D. (2000). The unity and diversity of executive functions and their contributions to complex "frontal lobe" tasks: A latent variable analysis. Cognitive psychology, 41(1), 49-100. https://doi.org/10.1006/cogp.1999.0734

Norgaard, M., Stambaugh, L. A., \& McCranie, H. (2019). The effect of jazz improvisation instruction on measures of executive function in middle school band students. Journal of Research in Music Education, 67(3), 339-354. http://doi.org/10.1177/0022429419863038

Putkinen, V., Tervaniemi, M., Saarikivi, K., \& Huotilainen, M. (2015). Promises of formal and informal musical activities in advancing neurocognitive development throughout childhood. Annals of the New York Academy of Sciences, 1337(1), 153-162. https://doi.org/10.1111/nyas.12656

Rickard, N. S., Appelman, P., James, R., Murphy, F., Gill, A., \& Bambrick, C. (2013). Orchestrating life skills: The effect of increased school-based music classes on children's 
social competence and self-esteem. International Journal of Music Education, 31(3), 292-309. https://doi.org/10.1177/0255761411434824

Riggs, N. R., Jahromi, L. B., Razza, R. P., Dillworth-Bart, J. E., \& Mueller, U. (2006). Executive function and the promotion of social-emotional competence. Journal of Applied Developmental Psychology, 27(4), 300-309. https://doi.org/10.1016/j.appdev.2006.04.002

Sala, G., \& Gobet, F. (2017). When the music's over. Does music skill transfer to children's and young adolescents' cognitive and academic skills? A meta-analysis. Educational Research Review, 20, 55-67.https://doi.org/10.1016/j.edurev.2016.11.005

Sala, G., \& Gobet, F. (2020). Cognitive and academic benefits of music training with children: A multilevel meta-analysis. Memory \& Cognition, 48(8), 1429-1441. https://doi.org/10.3758/s13421-020-01060-2

Schäfer, T., Sedlmeier, P., Städtler, C., \& Huron, D. (2013). The psychological functions of music listening. Frontiers in Psychology, 4, 511. http://doi.org/10.3389/fpsyg.2013.00511

Schellenberg, E. G. (2011). Examining the association between music lessons and intelligence. British Journal of Psychology, 102(3), 283-302. https://doi.org/10.1111/j.2044$\underline{8295.2010 .02000 . x}$

Schellenberg, E. G., Corrigall, K. A., Dys, S. P., \& Malti, T. (2015). Group music training and children's prosocial skills. PLoS One, 10(10), e0141449. https://doi.org/10.1371/journal.pone.0141449 
Southgate, D. E., \& Roscigno, V. J. (2009). The impact of music on childhood and adolescent achievement. Social science quarterly, 90(1), 4-21. https://doi.org/10.1111/j.1540$\underline{6237.2009 .00598 . x}$

Swaminathan, S., Schellenberg, E. G., \& Khalil, S. (2017). Revisiting the association between music lessons and intelligence: Training effects or music aptitude? Intelligence, 62, 119124. https://doi.org/10.1016/i.intel1.2017.03.005

Xue, Y., Yang, Y., \& Huang, T. (2019). Effects of chronic exercise interventions on executive function among children and adolescents: A systematic review with meta-analysis. British Journal of Sports Medicine, 53(22), 1397-1404.https://doi.org/10.1136/bjsports$\underline{2018-099825}$

Zapata, G. P., \& Hargreaves, D. J. (2018). The effects of musical activities on the self-esteem of displaced children in Colombia. Psychology of Music, 46(4), 540-550. https://doi.org/10.1177/0305735617716756 